\title{
Heterogeneous preferences for domestic water quality service improvement: a mixed logit approach
}

\begin{abstract}
This paper reports the findings from choice experiment (CE) study designed to estimate the economic value of domestic water quality and services attributes in Damaturu, Yobe State Nigeria. The Mixed Logit Model (MLM) was used in order to estimate the household preferences and personal interviews were made on a total of 300 households. The households were asked to select the best among the alternatives of the domestic water quality and service improvements. The attributes investigated were tab water quality (TWQ), total supply of water (TWS), tap water pressures (TWP) and water billing price (P). Findings of the study show that the householdôs preferred the highest changed in each attributes levels. The most significant variable in MLM model is TWQ attribute, which marginal rate of substitution (MRS) is $685 \%$ for simple model and $572 \%$ for interaction model. The findings of this study can assist the government in designing cost effective management and efficient tariff structure.
\end{abstract}

Keyword: Choice experiment; Water quality; Willingness to pay; Mixed logit model; Heterogeneous attributes 